\title{
Effect of initial temper on mechanical properties of creep-aged Al-Cu-Li alloy AA2050
}

\author{
Yong $\mathrm{Li}^{1}{ }^{1}$ *, Yo-Lun Yang ${ }^{1}$, Qi Rong ${ }^{1}$, Zhusheng Shi ${ }^{1}$, Jianguo Lin ${ }^{1}$ and Rajab Said ${ }^{2}$ \\ ${ }^{1}$ Department of Mechanical Engineering, Imperial College London, London SW7 2AZ, UK \\ ${ }^{2}$ ESI Group, 100-102, Avenue de Suffren, 75015, Paris, France
}

\begin{abstract}
The evolution of mechanical properties of a third generation Al-Cu-Li alloy, AA2050, with different initial tempers (T34 and as-quenched (WQ)) during creep-ageing has been investigated and analysed in this study. A set of creep-ageing tests under $150 \mathrm{MPa}$ at $155^{\circ} \mathrm{C}$ for up to $24 \mathrm{~h}$ was carried out for both initial temper conditions and tensile tests were performed subsequently to acquire the main mechanical properties of the creep-aged alloys, including the yield strength, ultimate tensile strength (UTS) and uniform elongation. Precipitation behaviour of the T34 and WQ AA2050 alloys has been summarised and successfully explains the detailed evolutions of the obtained mechanical properties of the alloy with these two initial tempers during creep-ageing. The results indicate that the T34 alloy can be a better choice for creep age forming (CAF) process compared with WQ alloy, as it provides better yield strength and uniform elongation properties concurrently after creep-ageing. In addition, a work hardening rate analysis has been carried out for all the creep-aged alloys, helping to reveal the detailed dislocation/precipitates interaction mechanisms during plastic deformation in the creep-aged T34 and WQ AA2050 alloys.
\end{abstract}

Keywords: Sheet metal; Simulation; Forming.

\section{Introduction}

Creep age forming (CAF) is an advanced forming technology originally proposed to manufacture large/extra-large panels in the aerospace industry, in which the plastic deformation and age hardening occur simultaneously in the material during the process [1]. The creep-ageing behaviour of the recently developed third generation Al-Cu-Li alloy AA2050 has been investigated previously [2, 3], which indicated that the alloy is promising to be used for the aerospace components through CAF. For potential industrial applications, the detailed mechanical properties of the alloy after CAF are important, especially for the aerospace components, and therefore need be investigated and evaluated.

It has been widely reported that initial tempers could highly affect the precipitation progress of $\mathrm{Al}-\mathrm{Cu}-\mathrm{Li}$ alloys during artificial ageing and result in different yield strength properties of the aged alloys [4, 5]. Kumar et al. [4] investigated the effect of pre-stretch on ageing behaviour of a naturally-aged $\mathrm{Al}-\mathrm{Cu}-\mathrm{Li}$ alloy and indicated that pre-stretch can not only accelerate the age hardening speed of the alloy, but also assist the nucleation of $\mathrm{T}_{1}\left(\mathrm{Al}_{2} \mathrm{CuLi}\right)$ precipitates, enhancing the yield strength of the alloy. Similar phenomenon has also been observed in an as-quenched Al-Cu-Li alloy by Ringer et al. [5]. While for CAF process, the creep-ageing behaviour of an Al-Cu-Li alloy (AA2050) with different initial tempers, namely the as-quenched (WQ), T34 and T84, has also been investigated and compared, showing different creep strain and age hardening properties under the same stress level at $155^{\circ} \mathrm{C}$ [2]. However, only the yield strength of the alloys after creep-ageing was considered in previous studies, other mechanical properties, such as ultimate tensile strength (UTS) and uniform elongation, are also important for the CAFed alloys and should be considered as well, so as to provide a comprehensive way to select alloys with a proper initial temper condition for CAF applications.

Meanwhile, the plastic deformation behaviour of Al$\mathrm{Cu}-\mathrm{Li}$ alloys also attracts a lot of interest, as it can explain the strength and elongation properties of the alloys and also indicate the detailed dislocation/precipitates interaction mechanism during plastic deformation. Some earlier studies reported that $\mathrm{Al}-\mathrm{Cu}-\mathrm{Li}$ alloys with different precipitates after artificial ageing show different work hardening behaviour during plastic deformation, depending on the main precipitates in them (such as $T_{1}$ and/or $\delta^{\prime}\left(\mathrm{Al}_{3} \mathrm{Li}\right)$ ) [6-8]. As different precipitates exist in the alloys with different initial tempers after creep-ageing, their effects on the plastic deformation behaviour of particular alloys are also of interest.

Hence, in this paper, an Al-Cu-Li alloy, AA2050, with two commonly reported initial temper conditions, asquenched and naturally-aged, was used to investigate the

\footnotetext{
* Corresponding author: yong.li14@imperial.ac.uk
} 
initial temper effect on evolutions of mechanical properties, including yield strength, UTS and elongation, during creep-ageing in CAF. The plastic deformation behaviour of the creep-aged alloys is then discussed based on a work hardening rate analysis, so as to reveal the detailed dislocation/precipitates interaction mechanisms related to the mechanical properties of the creep-aged AA2050.

\section{Material and experiments}

\subsection{Material and heat treatment}

AA2050, a third generation Al-Cu-Li alloy provided by Embraer (Brazil), was used in this study. The main chemical composition of the alloy is listed in Table 1 below.

Table 1. Main chemical composition of AA 2050 (wt\%).

\begin{tabular}{|c|c|c|c|c|c|c|}
\hline $\mathrm{Al}$ & $\mathrm{Cu}$ & $\mathrm{Li}$ & $\mathrm{Mg}$ & $\mathrm{Ag}$ & $\mathrm{Mn}$ & $\mathrm{Zr}$ \\
\hline Balance & 3.6 & 0.9 & 0.34 & 0.35 & 0.34 & 0.08 \\
\hline
\end{tabular}

The material was received with a naturally-aged T34 initial temper, which has been solution heat treated (SHT), water quenched, pre-stretched and finally naturally-aged. The material with another initial temper condition, asquenched, was prepared from the as-received T34 material by solution heat treating (SHT) at $500^{\circ} \mathrm{C}$ for $1 \mathrm{~h}$, followed by water quenching. Fig. 1 shows the heat treatment procedures for material preparation and subsequent creep-ageing test in this study.

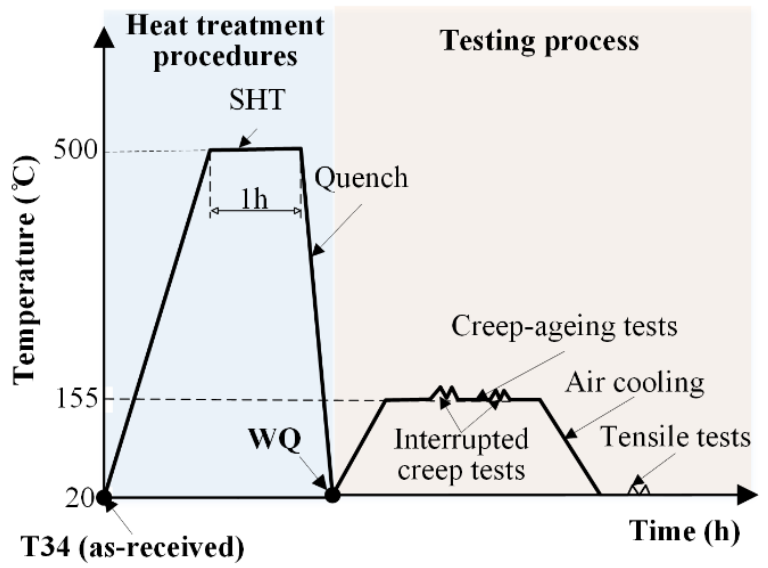

Fig. 1. Heat treatment procedures and test conditions

\subsection{Creep-ageing and tensile tests}

AA2050 alloy with T34 and WQ initial tempers was creep-aged under a constant stress level of $150 \mathrm{MPa}$ at $155^{\circ} \mathrm{C}$ for different durations, as listed in Table 2. For the alloy with WQ initial temper, creep-ageing tests were performed immediately after water-quenching.
Subsequent tensile tests were carried out at room temperature to obtain the main mechanical properties of the creep-aged alloys. The heat treatment condition for these tests is shown in Fig. 1.

Table 2. Experimental plan for creep-ageing and tensile test.

\begin{tabular}{|c|c|}
\hline Initial temper & Creep-ageing time (h) \\
\hline T34 & $0,2,5,8,12,18,22$ \\
\hline WQ & $0,5,12,18,24$ \\
\hline
\end{tabular}

Both creep-ageing and tensile tests were performed on an Instron 5584 machine. Fig. 2 shows the sample geometry used for both tests. A high temperature extensometer Instron 2620-601 was attached onto the sample to capture the strain during both tests.

For creep-ageing tests, an assisting furnace was used to provide the high temperature environment and the constant load was applied after the sample reached 155 ${ }^{\circ} \mathrm{C}$. For tensile tests, a strain rate of $10^{-4} / \mathrm{s}$ was used.

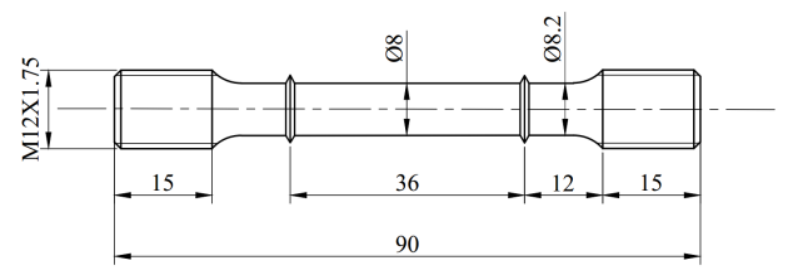

Fig. 2. Specimen geometry and dimension for creep-ageing and tensile tests (units: $\mathrm{mm}$ ).

\section{Evolution of precipitates}

The details of precipitation progress of AA2050 and other similar Al-Cu-Li alloys with T34 and WQ initial tempers during artificial ageing/creep-ageing have been investigated and discussed before $[2,5,6]$. A brief summary of the precipitation is given in this section to assist the further analysis of the current study, as listed in Table 3. Different microstructures have been observed in the initial state of T34 and WQ tempered AA2050 alloys. $\mathrm{Cu}$-rich clusters exist in T34 alloy and the WQ alloy shows a supersaturated solid solution (SSSS) condition. During artificial ageing, T34 alloys experience an initial dissolution of $\mathrm{Cu}$-rich clusters and accelerated nucleation of $\mathrm{T}_{1}\left(\mathrm{Al}_{2} \mathrm{CuLi}\right)$ precipitates (with some minor $\theta^{\prime}\left(\mathrm{Al}_{2} \mathrm{Cu}\right)$ / $\left.\mathrm{S}^{\prime}\left(\mathrm{Al}_{2} \mathrm{CuMg}\right)\right)$ occurs subsequently because of the dislocations in the alloys from pre-stretching. While for the WQ alloys, nucleation and growth of GP zones and $\delta$ ' $\left(\mathrm{Al}_{3} \mathrm{Li}\right)$ occur first and $\mathrm{T}_{1}$ precipitates (with some $\theta^{\prime} / \mathrm{S}^{\prime}$ ) start to nucleate and grow afterwards. Hence, in the peakaged state, different precipitates are observed in the T34 and WQ alloys. The peak-aged T34 alloys contain mainly $\mathrm{T}_{1}$ precipitates with some $\theta^{\prime} / \mathrm{S}^{\prime}$, while the peak-aged WQ alloys have both $\mathrm{T}_{1}$ and $\delta$ ' precipitates, along with some $\theta ' / S^{\prime}$. 
Table 3. Summary of main precipitates during artificial ageing/creep-ageing of AA 2050 with $\mathrm{T} 34$ and WQ initial tempers at $155{ }^{\circ} \mathrm{C}$ (summarised from $[2,5,6]$ ).

\begin{tabular}{|c|c|c|c|}
\hline Initial temper & Initial & Under-aged & Peak to Over-aged \\
\hline T34 & Cu clusters & $\begin{array}{c}\text { Dissolution of Cu clusters } \rightarrow \text { Nucleation and growth of } \\
\left.\text { precipitates (mainly } \mathrm{T}_{1} \text { with some } \theta^{\prime} / \mathrm{S}^{\prime}\right)\end{array}$ & $\begin{array}{c}\text { Majority of } \mathrm{T}_{1} \text { with some } \\
\theta^{\prime} / \mathrm{S}^{\prime}\end{array}$ \\
\hline WQ & $\mathrm{SSSS}$ & $\begin{array}{c}\text { Nucleation and growth of GP zones and } \delta^{\prime} \rightarrow \text { Nucleation } \\
\text { and growth of } \mathrm{T}_{1} \text { and some } \theta^{\prime} / \mathrm{S}^{\prime}\end{array}$ & $\mathrm{T}_{1}$ and $\delta^{\prime}$ with some $\theta^{\prime} / \mathrm{S}^{\prime}$ \\
\hline
\end{tabular}

\section{Results and discussion}

\subsection{Mechanical properties}

Test results for the yield strength, UTS and uniform elongation of the creep-aged T34 and WQ AA2050 alloy are presented and discussed in this section.

\subsubsection{T34 initial temper}

Fig. 3 shows the tensile test data of the T34 AA2050 alloy creep-aged under $150 \mathrm{MPa}$ at $155^{\circ} \mathrm{C}$ for different time. According to the stress-strain curves shown in Fig. 3(a), the as-received T34 alloy shows a relatively high yield strength of about $269 \mathrm{MPa}$ with a significant work hardening behaviour. In addition, apparent serrations, known as the Portevin-Le Chatelier effect, can be observed in the stress-strain curve of the as-received T34 alloy. This phenomenon may indicate that only minor stable clusters exist in the as-received alloy and hence, sufficient solutes in the alloy matrix can diffuse around dislocations to restrain its movement, leading to the observed serrations during plastic deformation $[9,10]$.

After $2 \mathrm{~h}$ of creep-ageing, the yield strength of the alloy drops to about $245 \mathrm{MPa}$, which has been explained as the dissolution of the naturally-aged $\mathrm{Cu}$ clusters in the T34 alloy. After that, yield strength increases with the creep-ageing time and nearly recovered to the as-received level $(269 \mathrm{MPa})$ at about $5 \mathrm{~h}$ creep-ageing. Significant serrations are also observed in the stress-strain curve of the $2 \mathrm{~h}$ creep-aged T34 alloy, reflecting the dissolution of clusters in the first $2 \mathrm{~h}$ of creep-ageing. For the $5 \mathrm{~h}$ creepaged T34 alloy, only slight serrations can be found, indicating that nucleation and growth of precipitates begin and less free diffused solutes exist in the matrix [9].

After $5 \mathrm{~h}$ creep-ageing, accelerated nucleation and growth of $T_{1}$ precipitates occurs, resulting in the dramatical increase of yield strength until peak-ageing occurs after $18 \mathrm{~h}$ creep-ageing, with a maximum yield strength of about $498 \mathrm{MPa}$. In addition, serrations in stress-strain curves disappear with the present of $T_{1}$ precipitates after $5 \mathrm{~h}$ creep-ageing. Subsequently, yield strength starts to slightly decrease along the creep-ageing time, which corresponds well with some previous studies [8].

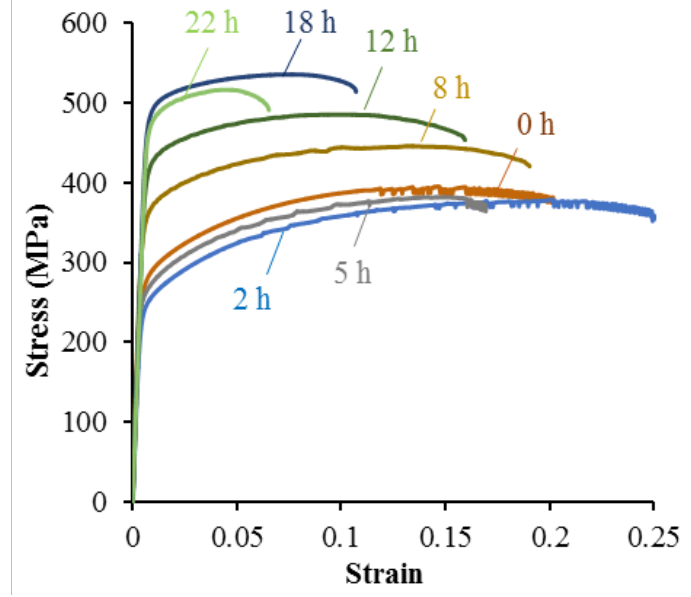

(a)

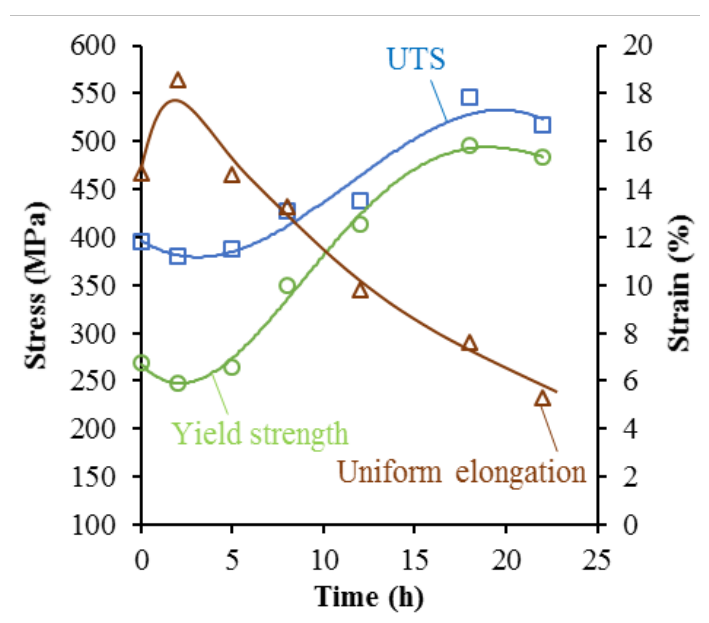

(b)

Fig. 3. (a) Stress-strain curves for T34 AA2050 creep-aged under $155 \mathrm{MPa}$ at $155{ }^{\circ} \mathrm{C}$ with indicated durations and (b) resultant yield strength, UTS and uniform elongation of the creep-aged alloys.

Fig. 3(b) illustrates the evolutions of yield strength, UTS and uniform elongation data during creep-ageing of T34 alloys. UTS shares the similar pattern with yield strength along the creep-ageing time, dropping down in the first $2 \mathrm{~h}$ creep-ageing and increasing substantially up to $18 \mathrm{~h}$. However, the difference between UTS and yield strength becomes smaller with increasing creep-ageing time, indicating a weakened work hardening behaviour because of the well-developed precipitates [8].

\footnotetext{
* Corresponding author: yong.li14@imperial.ac.uk
} 
Meanwhile, the uniform elongation evolves oppositely with yield strength and UTS, increasing at the first $2 \mathrm{~h}$ and decreasing afterwards.

\subsubsection{WQ initial temper}

Fig. 4 shows the same tensile data for various creep-aged AA2050 with WQ initial temper. The initial WQ alloy is with SSSS state and exhibits a comparative low yield strength of $117 \mathrm{MPa}$. However, substantial work hardening behaviour occurs in the alloy and its stressstrain curve demonstrates significant serrations, reflecting its precipitates free condition $[8,10]$.

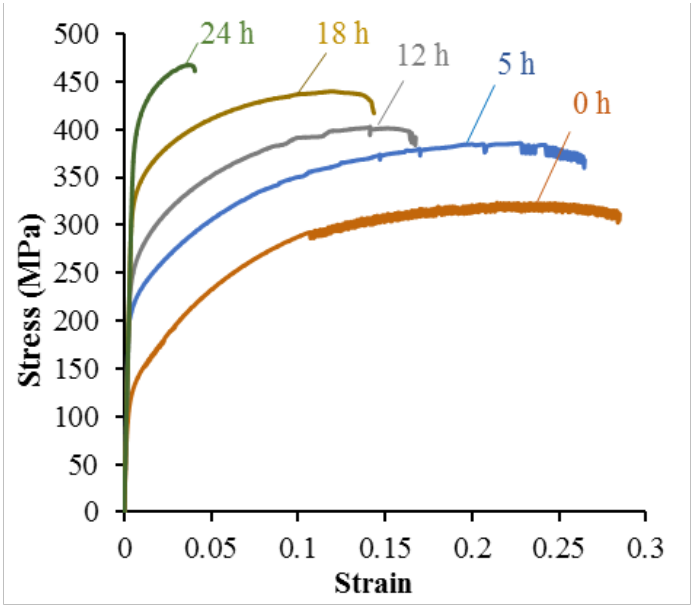

(a)

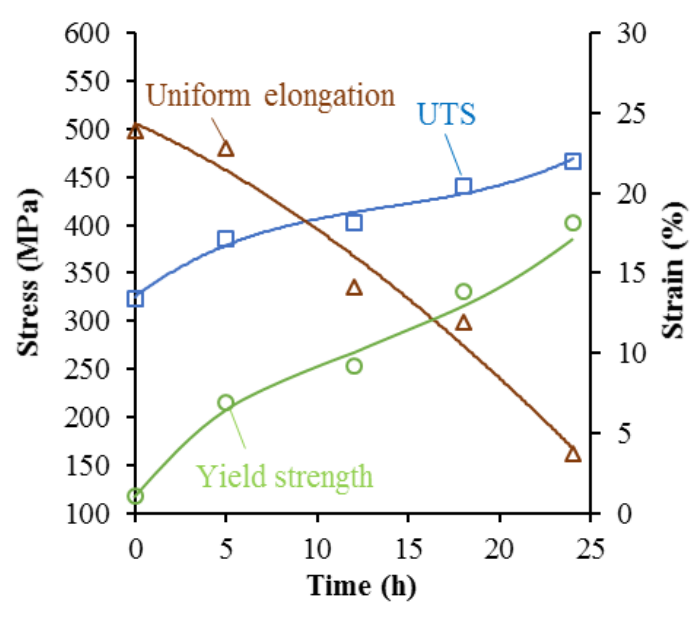

(b)

Fig. 4. (a) Tensile curves of AA2050 with WQ initial temper creep-aged under $155 \mathrm{MPa}$ at $155^{\circ} \mathrm{C}$ for different time durations and (b) resulted yield strength, UTS and uniform elongation of the creep-aged alloys.

The yield strength increases continuously along the creep-ageing time for WQ AA2050 alloys, because of the nucleation and growth of precipitates. However, in the early stage of creep-ageing, within $12 \mathrm{~h}$ at $155^{\circ} \mathrm{C}$ in this study (Fig. 4(a)), serrations still exist in the stress-strain curves of the creep-aged WQ alloys. Deschamps et al. [8] observed the same phenomenon in artificial ageing of AA2196 at the same stage where $\delta$ ' precipitates control yield strength and indicated that it may relate to the properties of precipitates. After $12 \mathrm{~h}$ creep-ageing, yield strength increases with a higher speed and serrations disappear in corresponding stress-strain curves because of the nucleation and growth of $\mathrm{T}_{1}$ precipitates, as explained in [8]. The alloy is still in under-aged condition after $24 \mathrm{~h}$ creep-ageing and the yield strength reaches $402 \mathrm{MPa}$.

The UTS data shares the similar trend with yield strength, as demonstrated in Fig. 4(b). Similar to T34 alloy results in Fig. 3(b), the level of work hardening strength (difference between UTS and yield strength) decreases with increasing creep-ageing time and a much higher decreasing speed can be observed after $12 \mathrm{~h}$, when $\mathrm{T}_{1}$ precipitates start to nucleate. The uniform elongation of the creep-aged WQ alloys, on the other hand, decreases continuously with the creep-ageing time.

\subsubsection{Comparison}

As CAF is mainly used for manufacturing structural panel products, high properties of both strength and ductility of the creep-aged material are preferred. According to the tensile data in Figs. 3 and 4, it seems that after the same creep-ageing time, T34 AA2050 alloy has a higher yield strength, but with a lower uniform elongation compared to the WQ alloy.

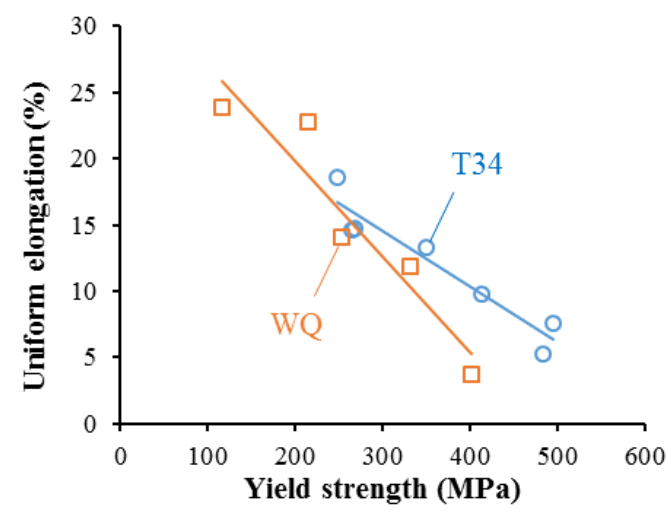

Fig. 5. Relationship between uniform elongation and yield strength for the creep-aged AA2050 with T34 and WQ initial tempers.

To evaluate the actual performance and relationship, the uniform elongation is plotted against the yield strength in Fig. 5 for the creep-aged T34 and WQ alloys. An inverse relationship can be seen between the yield strength and uniform elongation for both alloys. However, an interesting result is observed that with the same yield strength level, the creep-aged T34 alloy has a comparatively higher uniform elongation than the creepaged WQ alloy, indicating that AA2050 alloy with T34 initial temper could be a better choice for CAF process, as both comparatively high yield strength and uniform elongation can be achieved concurrently after creepageing. This phenomenon is believed to be related to the different precipitates in the creep-aged T34 and WQ alloys. As $\mathrm{T}_{1}$ precipitates contribute to a higher hardening effect and nucleated more homogenously than $\delta$ ' precipitates [11], better mechanical properties can be 
expected for the creep-aged T34 alloys that contain mainly $T_{1}$ precipitates, rather than WQ alloys, in which both $\mathrm{T}_{1}$ and $\delta$ ' exist.

\subsection{Work hardening analysis}

During tensile tests of the creep-aged alloys, the interaction between dislocations and precipitates determines the plastic deformation behaviour of the alloys. Work hardening analysis is carried out in this section to reveal the possible dislocation/precipitates interaction mechanism during plastic deformation of the creep-aged T34 and WQ AA2050 alloys. Kocks-Mecking plots [12] are used in this study for the work hardening analysis, as shown in Fig. 6, illustrating the evolution of work hardening rate $(d \sigma / d \varepsilon$, where $\sigma$ is the applied stress and $\varepsilon$ is the strain) against the work hardened strength ( $\sigma-\sigma_{y}$, where $\sigma_{y}$ is yield strength) for both T34 and WQ AA2050 alloys.

Generally, the creep-aged T34 and WQ alloys share similar work hardening behaviour, where the work hardening rate decreases with increasing hardened strength levels. For T34 alloys, when only solute clusters or minor precipitates (such as GP zones) exist during the early stage of creep-ageing (within $5 \mathrm{~h}$ in this study), similar work hardening rate can be observed in the alloy in Fig. 6(a). A very high initial work hardening rate (6000 to $8000 \mathrm{MPa}$ ) is observed at this stage because of the high free solute contents in the alloy matrix [8]. Similar work hardening rate is also observed in the as-quenched alloy with a SSSS condition, as shown in Fig. 6(b).

The work hardening rate behaviour starts to change when the main strengthening phases ( $T_{1}$ and $\delta$ ') start to substantially nucleate in the alloys. For T34 alloys, a lower initial work hardening rate with a higher dropping speed at the end part of the curves in Fig. 6(a) is observed after $5 \mathrm{~h}$ creep-ageing. The same trend can be observed in the creep-aged WQ alloy after $12 \mathrm{~h}$ creep-ageing according to Fig. 6(b). Moreover, the rate dropping speed increases in the material with longer creep-ageing time. Similar behaviour with ageing time has been reported in some Al-Cu-Li [8] and Al-Zn-Mg [13] alloys with shearable precipitates (such as $\delta$ ' and $\eta$ ') and has been explained as the occurrence of shearing of precipitates during plastic deformation in tensile tests. Deschamps et al. [8] has reported that $T_{1}$ precipitate is a semi-shearable precipitate, which exhibits a single-time shearing property. Hence, shearing can be observed in creep-aged T34 alloys with dominant $T_{1}$ precipitates during tensile tests, leading to the lower initial work hardening rate with a higher dropping speed at the end of the Kocks-Mecking curves after $5 \mathrm{~h}$ creep-ageing [8]. Meanwhile, for the creep-aged WQ alloys, in which both $\mathrm{T}_{1}$ and $\delta$ ' exist, a much higher dropping speed of the work hardening rate is expected as $\delta$ ' has a higher shearable property than $\mathrm{T}_{1}$, as shown in Fig. 6 (b) for the $24 \mathrm{~h}$ creep-aged WQ alloy.

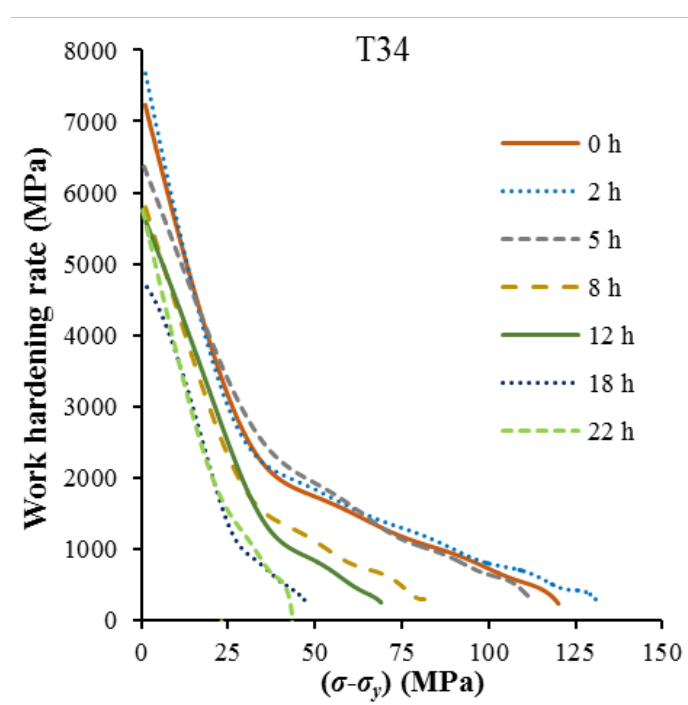

(a)

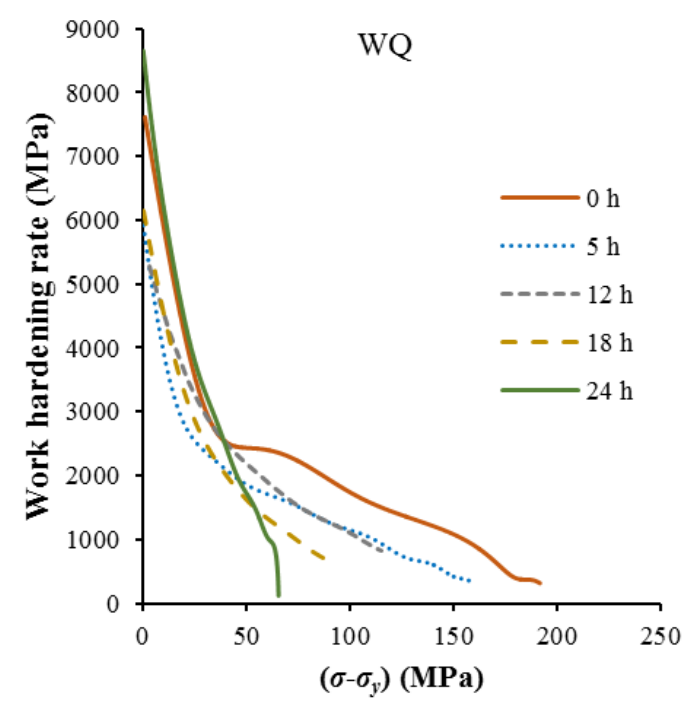

(b)

Fig. 6. Evolution of work hardening rates with the hardening strength $\left(\sigma-\sigma_{y}\right)$ for AA2050 with (a) T34 and (b) WQ initial tempers creep-aged under $155 \mathrm{MPa}$ at $155{ }^{\circ} \mathrm{C}$ for indicated durations.

\section{Conclusions}

In this study, main mechanical properties of AA2050 with T34 and WQ initial tempers, creep-aged under $150 \mathrm{MPa}$ at $155^{\circ} \mathrm{C}$ for various time, have been investigated and a work hardening analysis has been carried out to reveal the dislocation/precipitates interaction mechanism during tensile tests. The following conclusions can be drawn:

1) The yield strength of T34 AA2050 alloys drops from 269 to $245 \mathrm{MPa}$ within the first $2 \mathrm{~h}$ of creep-ageing because of dissolution of $\mathrm{Cu}$-clusters. It subsequently increases and reaches peak-ageing state with a yield strength of $498 \mathrm{MPa}$ after $18 \mathrm{~h}$. UTS shares similar behaviour with yield strength while the uniform elongation demonstrates an exactly opposite behaviour. For WQ AA2050 alloys, the yield strength and UTS 
increase with creep-ageing time in the tested range up to $24 \mathrm{~h}$, while uniform elongation decreases conversely.

2) T34 alloy is shown to be a better choice for CAF process than WQ alloy, as the creep-aged T34 alloy achieves a higher uniform elongation than the creep-aged WQ alloy with the same yield strength.

3) The different mechanical properties and work hardening behaviour of creep-aged alloys with T34 and WQ initial tempers can be explained by their precipitation behaviour. Creep-aged T34 alloys contain mainly $\mathrm{T}_{1}$ precipitate, resulting in a higher strength and slight lower work hardening rate dropping speed than the creep-aged WQ alloys, in which both $\mathrm{T}_{1}$ and $\delta$ ' precipitates are present concurrently.

\section{Acknowledgements}

The authors would like to thank the financial support from ESI Group (France) and the provision of material by Embraer (Brazil).

\section{References}

1. L. Zhan, J. Lin and T. A. Dean, Int. J. of Mach. Tool. Manu. 51, 1 (2011): 1-17.

2. Y. Li., Z. Shi, J. Lin, Y-L. Yang, B-M. Huang, T-F. Chung and J-R. Yang, Mater. Sci. Eng.: A. 657 (2016): 299-308.

3. Y. Li, Z. Shi, J. Lin, Y-L. Yang, Q. Rong, B-M. Huang, T-F. Chung, Ch-S. Tsao, J-R. Yang and D. Balint, Int. J. Plasticity. 89 (2017): 130-149.

4. K. S. Kumar, S. A. Brown and J. Pickens, Acta Mater. 44, 5 (1996): 1899-1915.

5. S. P. Ringer, B. C. Muddle and I. J. Polmear, Metall. Mater. Trans. A. 26, 7 (1995): 1659-1671.

6. B. Decreus, A. Deschamps, F. De Geuser, P. Donnadieu, C. Sigli and M. Weyland, Acta Mater. 61, 6 (2013): 2207-2218.

7. A. Csontos and E. A. Starke, Int. J. Plasticity. 21, 6 (2005): 1097-1118.

8. A. Deschamps, B. Decreus, F. D. Geuser, T. Dorin and M. Weyland, Acta Mater. 61 (2013): 4010-4021.

9. P. G. McCormick, Acta Metall. 19, 5 (1971): 463471.

10. D. Thevenet, M. Mliha-Touati and A. Zeghloul, Mater. Sci. Eng.: A. 266, 1 (1999): 175-182.

11. W. A. Cassada, G. J. Shiflet and E. A. Starke, Metall. Trans. A. 22, 2 (1991): 299-306.

12. U.F. Kocks and H. Mecking, Prog. Mater. Sci. 48 (2003): 171-273.

13. G. Fribourg, Y. Bréchet, A. Deschamps and A. Simar, Acta Mater. 59 (2011): 3621-3635. 